\title{
Need Analysis in Development of Production Based Learning
}

\author{
Heri Yudiono ${ }^{1}$ \\ \{heri yudiono@mail.unnes.ac.id\} \\ ${ }^{1}$ Mechanical engineering of Department, Universitas Negeri Semarang, Indonesia
}

\begin{abstract}
The development of vocational education learning requires a needs analysis to ensure that the quality of learning process and outcomes is appropriate with the expected objectives. Needs analysis identifies carefully and in detail the needs of the learning process. This study aims to analyze personal, skills, organization, and facility needs in developing production-based learning models through aligning competencies with industry. The research method used descriptive research with a calculated average. The mapping of knowledge, skills and attitudes are owned by $91.67 \%$ of the personal needs. Communication and collaboration skills needs are $93.33 \%$. Creativity and critical thinking need in completing work is $92.50 \%$ of the skill needs. Clarity of objectives, procedures, and standard operating procedure for learning implementation is $92.50 \%$ of the facility need. Needs analysis in developing production-based learning model are: 1) industry internship, competency mapping; 2) soft skills development and harmony with work culture; 3) Goals and performance targets alignment, and 4) Standard Operating Procedure (SOP) in learning
\end{abstract}

Keywords: Needs analysis, Production-based learning, Competency alignment

\section{Introduction}

Vocational education is an educational institution that prepare graduates to work in harmony with industry and community needs. Vocational education urgency must be seen from various dimensions. Student's dimensions expect improvement in self-competence, opportunities to work, prepare further studies, and adapt to change. Business world's dimensions obtain high quality worker, ease business financing, and business world development. Vocational education also has multi functions. If managed properly vocational education can give great contribution for the national development goals. Vocational education plays a strategic role in produces competent workforce that is globally competitive and promotes sustainable development. Vocational education pro-employment, pro-activity, pro-growth, pro-distribution, and pro-prosperity (Yudiono, et al., 2018).

Vocational education has great urgency, so sustainable adaptation and anticipation to changes is needed. Changes in vocational education are carried out through curriculum reengineering and learning innovation. Reengineering has positive impact on both vocational education and graduates quality. Vocational education curriculum must be aligned with the competency needed by industry. Curriculum as a spirit in vocational education must be aligned regularly with the changes in competency needed by industry. Curriculum changes also impact in the learning model used. Teachers always make innovation in learning to adjust curriculum changes. Learning innovation 
encourage vocational education to implement learning processes that can actually build productive competencies, such as product-based learning, projection-based learning, and others.

Production-based learning is integrating production activities in the industry into learning activities in schools. Alignment of industry competence with the vocational education curriculum becomes the spirit of a production-based learning model to obtain competency mapping. The competency mapping determine product or design that will produce by student in school or industry based on the adequacy of facilities. Implementation of industrial production-based learning using the ACDIE model (Alignment, Conceive, Design, Implement, Evaluation). Alignment Stage is the most important stage in synchronizing the competencies need with industry. This stage determines the types of products that will make by consider the competencies achieved, the equipment used, the implementation of learning and the strengthening of work culture. The Conceive stage strengthens the understanding in production-based learning process, where students with the guide from teachers discuss the learning process and determine the products that will be produced. The Design stage creates detail designs based on alternative product choices. In the implementation stage, students start production process through learning activities and mentoring by the teacher. The evaluation phase is carried out through assessment on the process and the final product. Students present the performance of the process and the products produced. The alignment stage is the most important stage to analyze production-based learning model needs. The needs analysis at this stage is carried out in detail by using the priority scale so the alignment results support the next stage. Needs analysis is a preliminary study to assess the needs for develop education quality (Garira, 2020).

Needs analysis plays important role in education development so the implementation appropriate with the expected goals. Needs analysis avoids the gap between the expected goals and the real conditions of the learning process. Learning needs analysis is needed for identifying relevant needs based on priorities. Learning needs analysis determine actions and provide data in order to analyze learning effectiveness. Identification of learning needs determines student's competency gap, appropriateness learning activities, and the accuracy of the targets that follow the activities. Needs analysis is process to determine and deal about needs because of the gap between the current conditions and desired conditions (Klaharn, 2017). Based on these problems, this study analyzes personal, skills, organization, and facility needs in developing production-based learning models through aligning competencies with industry to improve mechanical skills.

\section{Methodology}

This research approach used descriptive method. Thirty research subjects consisted of mechanical engineering teachers and lecturers, industry partners, vocational education policy makers. Data collection used questionnaire to analyze personal, skills, organizational, and facilities needs with predetermined criteria. The research data were processed using descriptive statistics with a calculated average in Table 1. 
Table 1. Needs interpretation

\begin{tabular}{|c|c|c|}
\hline No & Criteria & Percentage $(\%)$ \\
\hline 1 & Very needed & $76-100$ \\
\hline 2 & Needed & $51-75$ \\
\hline 3 & Less needed & $26-50$ \\
\hline 4 & Not needed & $0-25$ \\
\hline
\end{tabular}

\section{Results}

The results revealed that the analysis criteria for personal, skills, organization, and facility needs in develop production-based learning through aligning competencies with industry. Personal needs analysis show mapping of knowledge, skills and attitudes currently reached $91.67 \%$ from the required criteria. Industrial internships in order to improve student's and teacher's competency are $92.50 \%$ from the required criteria. Mechanical skills certification development is $86.67 \%$ from the personal needs. Teamwork development in competency alignment between the school and industry is $86.67 \%$ from the required criteria, while the entrepreneurship development is $84.17 \%$. Overall results of personal needs analysis in developing production-based learning model is $88.33 \%$ from the predetermined criteria. The results of the analysis of personal needs is shown in Table 2.

Table 2. Personal needs analysis

\begin{tabular}{clc|c}
\hline Number & \multicolumn{1}{c|}{ Criteria } & Percentage (\%) & Interpretation \\
\hline 1 & $\begin{array}{l}\text { Mapping of current knowledge, skills and } \\
\text { attitudes }\end{array}$ & 91.67 & Very needed \\
\hline 2 & Industrial internship & 92.50 & Very needed \\
\hline 3 & $\begin{array}{l}\text { Mechanical skills certification } \\
\text { development }\end{array}$ & 86.67 & Very needed \\
\hline 4 & $\begin{array}{l}\text { Improvement in mentor's pedagogical } \\
\text { competency }\end{array}$ & 88.33 & Very needed \\
\hline 5 & Teamwork development & 86.67 & Very needed \\
\hline 6 & Entrepreneurship development & 84.17 & Very needed \\
\hline & $\quad$ Total & 88.33 & Very needed \\
\hline
\end{tabular}

Skills analysis needs reach $89.03 \%$ of the criteria in developing production-based learning model through aligning competencies with industry. Skills needs analysis is needed in developing a production-based learning model. Working skill adequacy is $85.83 \%$ from the skill needed. Expertise standard adequacy expected by the industry partner from the learning reach $85.83 \%$ from the needs. Mentoring ability in implementation of the learning model is $85.83 \%$ and application of industry culture in increasing student soft skills reaches $90.83 \%$ from the skills need analysis for 
learning model development. Skill needs analysis in developing production-based learning model through aligning competencies with industry are shown in Table 3.

Table 3. Skills needs analysis

\begin{tabular}{clc|c}
\hline \multirow{2}{*}{ Number } & \multicolumn{1}{c|}{ Criteria } & Percentage (\%) & Interpretation \\
\hline 1 & Working skill adequacy & 85.83 & Very needed \\
\hline 2 & $\begin{array}{l}\text { Expertise standard adequacy that expected } \\
\text { by the industry partner }\end{array}$ & 85.83 & Very needed \\
\hline 3 & Mentoring ability & 85.83 & Very needed \\
\hline 4 & Industrial culture application & 90.83 & Very needed \\
\hline 5 & $\begin{array}{l}\text { Creativity and critical thinking on job } \\
\text { solving }\end{array}$ & 92.50 & Very needed \\
\hline 6 & Communication and collaboration ability & 93.33 & Very needed \\
\hline & $\quad$ Total & 89.03 & Very needed \\
\hline
\end{tabular}

Production-based learning development through aligning competencies with industries partner requires $86.46 \%$ joint and sustainable organizational management. Organizational management criteria is needed when developing learning models. Goals and performance targets alignment contribute $89.17 \%$ inorganization management needs for developing learning models. Organizational needs analysis in developing learning model require $85.83 \%$ human resource partnerships management. Organizational needs require $81.67 \%$ resource partnership to support the implementation of learning models and $89.17 \%$ harmony with work culture in improving student soft skills. Table 4. show the results of the organizational need analysis in developing productionbased learning model.

\begin{tabular}{clc|c}
\multicolumn{5}{c}{ Table 4. Organizational needs analysis } \\
\hline Number & Criteria & Percentage (\%) & Interpretation \\
\hline 1 & Goals and performance alignment & 89.17 & Very needed \\
\hline 2 & Resource development partnership & 85.83 & Very needed \\
\hline 3 & Resource partnership & 81.67 & Very needed \\
\hline 4 & Work culture alignment & 89.17 & Very needed \\
\hline & Total & $86.46 \%$ & Very needed \\
\hline
\end{tabular}

Facility needs analysis contributed $87.17 \%$ in developing production-based learning model through industrial competencies alignment. Identification and mapping of learning facilities reach $87.50 \%$ of the facility needed in implementing production-based learning. SOP Standard Operating Procedure (SOP) in the implementation of learning require $92.50 \%$ of the facilities needed. Development of learning models require $92.50 \%$ clarity of objectives and procedures for implementing activities. Conflict management criteria require $82.50 \%$ of the learning model need, conflict management are very needed when problems arise. Facility need requires $80.83 \%$ resource 
sharing implementation in supporting the development of learning models based on alignment with industry. The results of need analysisin developing learning models are shown in Table 5.

Table 5. Facility needs analysis

\begin{tabular}{clc|c}
\hline Number & \multicolumn{1}{c|}{ Criteria } & Percentage (\%) & Interpretation \\
\hline 1 & $\begin{array}{l}\text { Learning facility identification and } \\
\text { mapping }\end{array}$ & 87.50 & Very needed \\
\hline 2 & SOP in learning implementation & 92.50 & Very needed \\
\hline 3 & Objectives and procedure clarity & 92.50 & Very needed \\
\hline 4 & Conflict management & 82.50 & Very needed \\
\hline 5 & Resources sharing Implementation & 80.83 & Very needed \\
\hline & Total & 87.17 & Very needed \\
\hline
\end{tabular}

\section{Discussion}

This study analyze personal, skills, organization and facility needs based on predetermined criteria for developing production-based learning models through competency alignment. The results of needs analysis determine priority criteria in developing learning model. The results show that the priority scale of personal needs analysis is: 1) industry internships, 2) mapping of current knowledge, skill and attitude, 3) improvement in mentor's pedagogical competency, 4) mechanical skill certification Development, 5) teamwork development, and 6) entrepreneurship development. Industry internships play important role to improve the teacher's and student's competency. Industry internships give attention to competency mapping in learning achievement and availability of competencies in the industry. Competency mapping is an integral part of internships. Teachers as agents of change must have superior competency. Excellent teacher competency has great impact on increasing the student's competency in industry internships. Industry internships are the best way to apply theoretical and conceptual knowledge in to actual learning, increasing discipline that appropriate with industrial work culture (Tindowen, et al. 2019). Industrial internships also have impact on student's skills improvement (Sahrir, et al. 2016).

The priority scale of the skill needs in developing production-based learning model includes: 1) communication and collaboration skills, 2) creativity and critical thinking in completing work, 3) application of work culture, 4) skill standards suitability, 5) mentoring ability, and 6) working skills adequacy. Soft skills development becomes the priority for the development of learning models and the skills needed by industry. Communication skills, collaboration, creativity, and critical thinking integrated in production based learning can improve student's soft and hard skills (Yudiono, et al. 2019). The competency needs are not only significant resource management and mechanical knowledge strengthening, but also developing the competency requirements needed by the industry. The industry requires both the competitiveness development and ability to innovate when facing rapid changes (Palma, et al. 2012).

Organization needs priority scales in developing production-based learning model such as: 1) performance goals and objectives alignment, 2) harmony of work culture, 3) human resource development partnerships, and 4) resource partnerships. Between vocational education and industry partners must have an understanding in formulating goals, performance targets especially graduate 
competencies, building work culture, and developing resources. Partnerships must be formulated together by involving relevant stakeholders. Partnerships need to be institutionalized to improve alignment performance. An alignment agency develops a competency alignment framework, optimizes the role of industry and policy makers, resources development and empowerment, integrates competencies into the curriculum and implementation of learning, and evaluates the performance of alignment comprehensively (Yudiono, 2017). Educational cooperation with industry will be more meaningful and beneficial if it is institutionalized. Evaluation of partnerships is done through evaluating the transfer of knowledge and technology of both parties, industry and university are complementary, so cooperation must build legally (Candan and Nuriye, 2010). Strategy to build sustainable partnerships is strengthening the commitment of related parties, promoting cooperation, sharing and strengthening the content of cooperation, and spreading professional knowledge (Xiang and Yuan, 2019). The harmony of work culture is implemented in teaching and learning activities to familiarize students in their environment later. Vocational education will be effective if training experience is dedicated to build work and correct thinking habits so it is appropriate for their future jobs (Prosser and Quigley, 1959).

Priority scales of need facilities in developing learning models is: 1) clarity of objectives and procedures, 2) standard operating procedure in implementation, 3) identification and mapping of learning tools, 4) conflict management, and 5) resource sharing implementation. It is undeniable that learning quality is greatly influenced by adequate facilities and infrastructure. Vocational education will be effective if the training assignments are carried out in the same manner, tools and machinery as those applied in the workplace (Prosser \& Quigley, 1959). Implementation of learning requires facilities that can support its performance so learning is interesting and has impact on increasing students' competency and learning experience.

\section{Conclusion}

The results of the need analysis in developing production-based learning model through aligning competencies with industry partners can be concluded:

1. The priority of personal needs in the learning models development is industry internship at $92.50 \%$, and the mapping of knowledge, skills and attitudes currently owned by $91.67 \%$.

2. The priority of skill needs is communication and collaboration skills is $93.33 \%$ of skills needs, and creativity and critical thinking in completing work is $92.50 \%$ of the priority.

3. Harmony of work culture, performance goals and objectives is $89.17 \%$ of the priority organizational needs.

4. Clarity of objectives and procedures, and the SOP of learning implementation is $92.50 \%$ of the priority needs in the development of production-based learning model. 


\section{References}

[1] Candan, D. A. and Nuriye, Ç. I. 2010. University-industry cooperation in terms of textile-apparel Education. Procedia Social and Behavioral Sciences 2 (2010) 3437-3441. doi:10.1016/j.sbspro.2010.03.530.

[2] Garira, E. 2020. Needs assessment for the development of educational interventions to improve quality of education: A case of Zimbabwean primary schools. Social Sciences \& Humanities Open 2 (2020) 100020. https://doi.org/10.1016/j.ssaho.2020.100020.

[3] Klaharn, R. 2017. The need assessment for improving the competence of thai Teachers in the measurement and evaluation of analytical thinking. International Journal of Teaching, Education and Learning Volume 1 Issue 2, pp. 1-16. DOI-https://dx.doi.org/10.20319/pijtel.2017.12.116.

[4] Palma, M., Ríos, I. D. L., Guerrero, D. 2012. Higher education in industrial engineering in Peru: towards a new model based on skills. Procedia - Social and Behavioral Sciences 46 ( 2012 ) 1570 - 1580. doi: 10.1016/j.sbspro.2012.05.342.

[5] Prosser, C. A. and Quigley. 1959. Vocational education in a democracy. Chicago, U.S.A: American Technical Society

[6] Sahrir, M. S., Ismail, T., Mustapha, N. H., Bakar, R. A., Man, S., Ahmad, M. A. \& Mokhtar, M. 2016. An evaluation of internship programme in improving graduate skills and marketability among Arabic language students in IIUM from the perspective of Malaysian job market. Journal of Education and Human Development, March 2016, Vol. 5, No. 1, pp. 206-212. DOI: 10.15640/jehd.v5n1a21.

[7] Tindowen, D. J., Bangi, J. and Parallag, J. C. 2019. Pre-service teachers' evaluation on their student internship program. International Journal of Learning, Teaching and Educational Research. Vol. 18, No. 10, pp. 279-291, October 2019. https://doi.org/10.26803/ijlter.18.10.18.

[8] Xiang, P. and Yuan, T. 2019. A collaboration-driven mode for improving sustainable cooperation in smart industrial parks. Resources, Conservation \& Recycling 141 (2019) 273-283. https://doi.org/10.1016/j.resconrec.2018.10.037.

[9] Yudiono, H., Pramono, and Basyirun. 2019. The hypothetic model of integrated production-based learning with the $21^{\text {st }}$ century learning skills in mechanical engineering. JurnalPendidikanTeknologidanKejuruan, Vol. 25, No. 1, May 2019,97-102. DOI: 10.21831/jptk.v25i1.23328.

[10] Yudiono, H. 2017. The alignment of productive competence on machinery between vocational education institutions and industry. World Transactions on Engineering and Technology Education. Vol.15, No.3, 2017. http://www.wiete.com.au/journals/WTE\&TE/Pages/Vol.15,\%20No.3\%20(2017)/10-YudionoH.pdf

[11] Yudiono, H., Soesanto \& Haryono. 2018. An industrial competency-based curriculum alignment model. World Transactions on Engineering and Technology Education.Vol.16, No.1, 2018. http://www.wiete.com.au/journals/WTE\&TE/Pages/Vol.16,\%20No.1\%20(2018)/03-Yudiono-H.pdf 